\section{La enseñanza}

de la lectura

en Colombia:

Enfoques pedagógicos, métodos, políticas y textos escolares en las tres últimas décadas del siglo xx

O ensino da leitura na Colômbia Enfoques pedagógicos, métodos, politicas e textos escolares nas ultimas três décadas do século XX

\section{Teaching Reading in Colombia} Pedagogical Approaches, Methods, Policies and Schoolbooks in the Last Three Decades of the Twentieth Century

Nylza Offir García Vera

Sandra Lucía Rojas Prieto**

* El artículo procede de la investigación "Manuales y textos escolares para la enseñanza inicial de la lectura en Colombia: trayectoria histórica y pedagógica en las últimas tres décadas del siglo XX", financiada por el Centro de Investigaciones de la Universidad Pedagógica Nacional, CIUP, durante dos fases (DSI-096-08 y DSI278-11).

** Profesoras de la Facultad de Educación de la Universidad Pedagógica Nacional.

\section{Resumen}

El artículo presenta los hallazgos más relevantes de una investigación documental que, en perspectiva histórica, caracteriza la enseñanza inicial de la lectura en Colombia durante el último tercio del siglo Xx. A partir de una revisión de las cartillas o textos escolares diseñados para este fin, se estudian en paralelo los enfoques pedagógicos preminentes, así como los métodos de enseñanza, en contraste con el discurso pedagógico oficial de la época.

\section{Palabras clave}

Historia de la enseñanza de la lectura, enfoques pedagógicos, métodos de lectura, textos escolares

\section{Resumo}

0 artigo apresenta os resultados mais relevantes duma pesquisa documentaria que, na perspectiva histórica, caracteriza o ensino inicial da leitura na Colômbia durante o último terço do século Xx. A partir de uma revisão das cartilhas ou textos escolares desenhados para este fim, estudam-se em paralelo os enfoques pedagógicos preeminentes, assim como os métodos de ensino, em contraste com o discurso pedagógico oficial da época.

\section{Palavras chave}

História do ensino da leitura, enfoques pedagógicos, métodos de leitura, textos escolares

\section{Abstract}

This article shows the most relevant findings from a document-based research that characterizes the initial teaching of reading in Colombia during the last three decades of the twentieth century, from a historical perspective. Primers and textbooks designed for this purpose are revised, simultaneously with the main pedagogical approaches and teaching methods. This information is contrasted with the official pedagogical discourse of that time.

\section{Key words}

History of reading teaching, pedagogical approaches, reading methods, school textbooks

Fecha de recepción: Abril 6 de 2015

Fecha de aprobación: Junio 12 de 2015

Pedagogía y Saberes No. 42 Universidad Pedagógica Nacional Facultad de Educación. 2015, pp. 43-60 


\section{Introducción}

$\mathrm{L}$ a enseñanza de la lectura es un objeto de estudio central en la formación de maestros, dado que este proceso se constituye en la piedra angular sobre la cual se erigen las bases de la cultura escolar. En Colombia, históricamente esta enseñanza ha estado regulada por las cartillas escolares, en tanto dichos libros, además de tener un vector ideológico, se construyen desde el fundamento específico de un método o de un enfoque. Así lo señalan algunos estudios que asumen la lectura como principal objeto de conocimiento en la escolarización inicial y que muestran una relación directa entre la cartilla y los enfoques pedagógicos dominantes en una determinada época (Cf. Rey, A., 2001; Cardoso, E., 2001, 2002; Rincón, B., 2003).

Tales estudios, que realizan un análisis de las cartillas para enseñar a leer entre las postrimerías del siglo XIX hasta la primera mitad del siglo XX, dan cuenta de esta memoria textual que refleja no solo las maneras de hacer escuela -en la selección de los contenidos, en los métodos y en el lugar otorgado al maestro- sino también las configuraciones sociales, culturales y pedagógicas en determinados momentos históricos. En efecto, como lo señala Escolano (2001), este tipo de libros escolares son "un espejo de la sociedad que los produce" (p. 13).

En el núcleo de estas indagaciones es posible identificar la transformación pero a la vez la permanencia de ciertas pedagogías de la lectura con sus propias concepciones, métodos y prácticas, dentro de las que se destacan la pedagogía objetiva, la pedagogía católica y la pedagogía activa. Esta última tomando vigencia, incluso, hasta entrado los años sesenta en el país.

En este marco de estudios, el presente artículo da cuenta grosso modo de una indagación documental en torno a los enfoques pedagógicos identificados para la enseñanza de la lectura y los métodos a los que dieron lugar, particularmente, en su institucionalización a través del discurso pedagógico oficial durante las últimas tres décadas del siglo Xx. En paralelo, ofrece algunos ejemplos de su lugar de concreción en las cartillas o textos escolares diseñados para este fin durante el período en estudio (1970-2000), que nos sitúa además en una época de importantes transformaciones tanto en la industria editorial como en el proceso de modernización del campo educativo en el país, dadas las relaciones emergentes entre Estado y organismos multilaterales, así como entre mercado y textos escolares.

Es de señalar que este viraje histórico operado durante el periodo en estudio, descentra la mirada ideológica bipartidista en la educación como eje de discusión política y pedagógica y se abre a un horizonte mundial que mostrará sus efectos y alcances en los procesos curriculares y didácticos en la escuela, y, en esa medida, logrará afectar el ámbito material y simbólico que constituyen los textos escolares para la enseñanza inicial de la lectura.

De esta manera, si es posible identificar en los albores y desarrollos del siglo xx ciertas pedagogías de la lectura - pedagogía objetiva, pedagogía católica y pedagogía activa-, nos preguntamos entonces ¿qué enfoques pedagógicos podrían identificarse al vaivén del proceso de modernización de la escuela en Colombia? ¿Qué permanece en la pedagogía de la lectura y qué cambia? Y, finalmente, ¿qué sucede con la cartilla escolar desde las huellas de la Alegría de leer de editorial Voluntad, hasta la proliferación de textos escolares provenientes de la industria editorial hacia finales del siglo inmediatamente anterior? Una aproximación a estas inquietudes está en lo que sigue.

\section{Los enfoques pedagógicos y los métodos para la enseñanza de la lectura}

A lo largo de la historia de la educación y la pedagogía, la discusión sobre un método de enseñanza va más allá de sus alcances didácticos y curriculares y se cruza con posturas del orden epistemológico, filosófico, e, incluso, psicológico, frente al sujeto de conocimiento. Para Zuluaga (1987), el 'método', además de ser considerado como una "serie de enunciados referentes a los procedimientos para enseñar y que define como sujeto de saber al maestro", guarda también relación "con la historia de la educación, con la historia de la pedagogía, con la obra de los pedagogos, con la epistemología" (Cf. p.190-191). En otro lugar, la misma autora afirma que las elaboraciones de los historiadores de la pedagogía "muestran que el método de enseñanza ha sido pensado desde la forma como conoce el hombre, así esa forma se haya transformado en sus relaciones conceptuales" (Zuluaga, 2003, p. 53).

De esta manera, la relación entre las teorías pedagógicas de una época y las prácticas educativas que se concretan en ciertos métodos es vinculante. Según Mougniotte (1996), en esta relación —entre teorías y prácticas - independientemente de que las primeras susciten a las segundas o a la inversa, o que entre ellas haya o no continuidad visible, no dejan de influir las unas sobre las otras. Para este autor, es la firmeza con la que se traza la solidaridad y la correspondencia de ciertos principios entre una teoría pedagógica y un procedimiento de enseñanza lo que hace que este se sedimente como método, es decir, que adquiera cierta estabilidad y cierto reconocimiento, de tal 
manera que pueda ser acogido por el cuerpo docente e, incluso, por los entes educativos oficiales. Se trata de un método, si "es pues en sentido estricto, un procedimiento organizado, formalizado y orientado a la obtención de una meta claramente establecida" (Mougniotte, 1996, p. 173).

A partir de estas consideraciones, se entiende que cada método -en este caso, nos referiremos concretamente a los métodos para la enseñanza de la lecturapondría en juego una teoría o enfoque pedagógico, lo cual implica ciertas perspectivas desde las cuales se conciben, de un lado, los objetos de saber y el saber para enseñar, el conocimiento mismo y su estatus y organización en áreas o disciplinas; $y$, de otro, el sujeto de conocimiento y la pregunta por el cómo conoce o aprende ${ }^{1}$. En consecuencia, privilegian algunos procedimientos, valores y contenidos por encima de otros. En una perspectiva más amplia los métodos se derivan también de una postura frente a la educación en sí misma, los fines que pretende alcanzar y su sentido en la esfera específica de las relaciones entre escuela, educación y sociedad.

En esa perspectiva, nuestras indagaciones ubican tres grandes enfoques pedagógicos que durante el último tercio del siglo xx permearon, en mayor o en menor medida, como veremos, el diseño de los materiales educativos (cartillas o texto escolar), los métodos y las prácticas de enseñanza de este objeto de saber escolar. La descripción que sigue da cuenta de tales enfoques y de los métodos a los que dieron lugar, contrastados posteriormente con algunas de sus huellas en las cartillas o textos escolares y con el discurso pedagógico oficial. En ese sentido, nos aproximamos a una historia reciente de la enseñanza inicial de la lectura en nuestro país.

\section{La educación nueva y el método global}

El enfoque de la educación nueva, siguiendo a Luzuriaga (1961), puede definirse como un movimiento pedagógico que cobró fuerza con la corriente progresista y pragmatista de Dewey y Kilpatrick en Estados Unidos, pero también con un conjunto de experiencias que desarrollaron los principios de la escuela activa en Europa, con Decroly y Freinet a la cabeza, entre muchos otros. Podríamos decir, en términos generales, que se trata de una corriente renovadora de la escuela y la pedagogía, que impugna los modelos transmisionistas, el saber fragmentado que reproducen las

1 No obstante, dicha relación entre teoría y método no implica necesariamente una simetría: la solidaridad es relativa, en tanto no se corresponden uno a uno el enfoque o teoría pedagógica con las estrategias, métodos, técnicas o prácticas de realización concretas en el aula. disciplinas en la escuela, la pasividad del estudiante, la memorización de contenidos sin aplicación práctica, etc., para propender por un contenido social de lo que se enseña, por un aprendizaje desde y para la vida misma.

Luzuriaga (1961) precisa las ideas esenciales contenidas en este movimiento pedagógico, que podemos sintetizar en vitalidad, actividad, libertad, infantilidad y comunidad, centradas todas en el principio general de la actividad del alumno (Cf. p. 14-17). Tales ideas o principios dieron lugar a unos métodos, entre los que se halla el método Decroly o método global. Y quizás no se halle en el país referencia más precisa de lo que significaron los intentos por instituir una educación nueva, y, en consecuencia, una pedagogía activa centrada en el niño, que las visitas de Decroly y el trabajo que de allí se derivó a partir de sus ideas pedagógicas y de su propuesta del método global y los centros de interés².

Lo cierto es que sus ideas y, en concreto, su método ideo-visual o global fue incorporado especialmente para la enseñanza de la lectura en las cartillas de Alegría de leer, de Evangelista Quintana, adoptadas para las escuelas de la República a partir de 1935. Este método se destaca como una expresión de la escuela activa, cuya repercusión duró, de acuerdo con algunos estudios, incluso entrados los años sesenta (Cf. Rincón, B., 2003) y del cual vemos su memoria reflejada en cartillas vigentes en los años setenta. Pero ¿en qué se centraron las ideas pedagógicas de Decroly? ¿En qué consistía su método? Para responder a ello es necesario aclarar, en primera instancia, que Decroly no propone un método específico y exclusivo para la enseñanza de la lectura, sino que tal enseñanza se inscribe en un marco más amplio de sus ideas sobre la educación, cuya concepción global e ideo-visual están en la base de su programa escolar. De esta manera, solo podemos comprender los procedimientos propuestos para enseñar a leer, en la medida en que se sitúan en los principios, reglas y criterios que orientaban la acción pedagógica desde su concepción educativa.

Así, inicialmente podríamos decir que Decroly (1950) planteaba la insuficiencia del sistema escolar de la época para responder a una escuela que educara para la vida y desarrollara todas las facultades humanas, más allá de la adquisición de las técnicas

2 Según Aline Helg (2001), tales centros de interés se oficializaron en Colombia a partir de 1935, teniendo como base la experimentación realizada por Nieto Caballero, desde 1932, en el Gimnasio Moderno y en algunas escuelas públicas de Bogotá (p. 158). No obstante, fruto de las ya reconocidas pugnas políticas entre los tradicionales partidos, las propuestas educativas y los enfoques pedagógicos estuvieron, a partir de ahí, al vaivén de la hegemonía de uno u otro partido. 
de lectura y escritura. Para el autor, existía allí una concepción errada de la escuela y de los programas y por ello interpela: “ $¿$ No son dos absurdos pretender realizar la escuela para la vida dentro de un cuartel sin vida, con una enseñanza de cosas inertes? ¿No es una insensatez pretender favorecer la evolución de las facultades del niño, condenándolo a la inmovilidad y al silencio durante las mejores horas del día y los años más hermosos de su existencia?" (Decroly, 1950, p. 8).

Más allá de que ello sea una responsabilidad exclusiva del maestro, Decroly ve el problema en la escuela misma y en su disposición, así como en el programa que se impone. Empezando por el ambiente que la circunda, la organización de los espacios, hasta la 'desnudez' de las paredes en las aulas, su propuesta va interrogando tal organización escolar y desde allí propone una transformación de los métodos y horarios, del programa escolar y de sus contenidos, que podrá ser llevada a cabo con experiencias iniciales dirigidas por maestros instruidos y conscientes de la necesidad de tales cambios.

De esta manera, frente a los defectos del programa escolary su relación con el pensamiento y el desarrollo del niño - poca cohesión entre las diferentes actividades, materias sin relación con sus interés y evolución, demasiadas lecciones y objetos diferentes, división de materias que rebasan la capacidad de asimilación y de memoria de los niños, predominio de los métodos verbales y ejercicios que no dan ocasión a la actividad personal espontánea del niño (Cf. Decroly, 1950, p. 25-26)—, optará por la aplicación de un programa de ideas asociadas: el estudio del niño y su medio y el empleo de los centros de interés, explicitado a través de rúbricas - temas y subtemas, ejercicios, reglas y principios para su desarrollo, juegos educativos, tiempos escolares para dedicar a cada unidad, etc. - y basado, según sus planteamientos, en la psicología del niño y las necesidades sociales.

Ahora bien, para llevar a cabo el método Decroly en la escuela es crucial, como él mismo lo señalaba, acudir a las tres grandes funciones psicológicas que pueden ser traducidas a su vez a tres tipos de ejercicios: los ejercicios de observación, que implican poner al niño en contacto directo con los objetos, los seres, los hechos, los acontecimientos (p. 54). En cuanto a la asociación, se refiere a aquellos ejercicios en los cuales el contacto directo con la realidad no es indispensable y, sobre todo, no es posible. En todo caso, para el autor es necesario realizar el trabajo de asociación de las ideas a partir de las lecciones de observación, el recuerdo de experiencias pasadas, la iconografía y también a partir de algunas nociones transmitidas por vía verbal ${ }^{3}$. Finalmente, los ejercicios propios de la expresión, que implican para el autor todo aquello que permite la traducción del pensamiento de una manera accesible a los demás y comprende por consiguiente "no solamente la palabra y la escritura, sino también el dibujo y sobre todo el trabajo llamado manual" (p. 68).

Los ejercicios de expresión intervienen de manera permanente en los de observación y asociación, pero ocupan especialmente el punto más importante en la enseñanza de la lectura. Aquí, el autor les otorga un poder especial a la vista y al carácter globalizador del pensamiento, lo que le permite situar su método ideo-visual en relación con la enseñanza de la lectura sin deletreo ${ }^{4}$. Así, sostiene:

En efecto cuando la lectura llega a este estadio, el tiempo que la mirada emplea para apoderarse de una frase es demasiado corto para permitir el análisis detallado y la descomposición. Se puede afirmar, por consiguiente, que el procedimiento habitual de la enseñanza de la lectura por vía fonética-auditiva, procediendo por el estudio de los sonidos y de las sílabas para llegar a una generalización, no tiene defensa desde el punto de vista psicológico. (Decroly, 1950, p. 71)

Pero para Decroly, tampoco desde el punto de vista pedagógico y metodológico se sostiene la enseñanza de la lectura por la vía de los métodos fonéticos:

Las leyes fundamentales del trabajo pedagógico son ir de lo concreto a lo abstracto, de lo simple a lo compuesto, de lo conocido a lo desconocido. Ahora bien, si puede defenderse que la sílaba es más simple que una palabra, o una frase, y que una vez conocida se la puede volver a encontrar en una palabra desconocida, no es cierto de ningún modo que la sílaba sea concreta, en tanto que la palabra y la frase sean abstractas. Al contrario es fácil demostrar que la frase amo a mamá es más concreta que amo, sin más ni menos, y sobre todo que "A" o que "mo". Entonces, bastará hacer de manera que la frase exprese una idea conocida del niño para que pueda permitir que

3 Decroly concibe especialmente cuatro grupos principales de objetos para hacer ejercicios de asociación: 1) los que se refieren a objetos y hechos desde el punto de vista actual y en el espacio - como en la geografía—; los que examinan la materia u objeto desde el punto de vista temporal o de asociación en el tiempo — con el uso de documentación gráfica, la visita de muesos, el cine, etc.—; los que se designan bajo el nombre de asociación de orden tecnológico o utilización y aplicación industrial de la técnica para resolver las necesidades humanas; y, finalmente, las asociaciones de causa-efecto de los fenómenos, el por qué y el cómo de estos (Cf. Decroly, 1950, p. 66-68).

4 Para sostener la supremacía del enfoque ideo-visual sobre el enfoque fonético-auditivo, el autor se remitirá a los argumentos expuestos ya en 1906 en la Revue Scientifique de París (Cf. Decroly, 1950, p. 70-71). 
se salven por lo menos dos principios de los tres. En cuanto al último: "ir de lo simple a lo compuesto" sería cosa de preguntarnos si debe prevalecer sobre las otras dos, si una cosa simple, abstracta, no es para el niño mucho más difícil que otra más compleja, pero concreta. (Decroly, 1950, p. 71-72)

En esa línea, según él mismo, la experiencia diaria demuestra lo contrario: al observar todo lo que nos rodea en su multiplicidad de formas, de aspectos y de movimientos, lo que se retiene es la parte principal, lo que constituye en síntesis la señal diferencial, pues se trata de una función valorizadora que permite ahorrar esfuerzos a nuestro sistema nervioso. De esta manera, la noción de conjunto prevalece siempre antes que la de las partes o los detalles y por ello, según él así se procede, en igual modo, con la lectura:

Pensad asimismo cómo os veis obligados, cuando deseáis leer una carta cuya escritura es confusa, a recorrer toda la frase, varias frases, toda la carta a veces, para adivinar el sentido de una palabra mal escrita. Observad también que para leer corrientemente es necesario resbalar sobre las frases, por decirlo así, sin detenerse en los detalles, es decir, contentarse con el esquema de las palabras, sin lo cual la escritura sería imposible. (Decroly, 1950, p. 73-74)

Finalmente, para el autor del método global, la experiencia desarrollada siguiendo este procedimiento demostró a los maestros su eficacia no solo en la enseñanza inicial de la lectura, sino también en la escritura y, concretamente, en el aprendizaje de la ortografía.

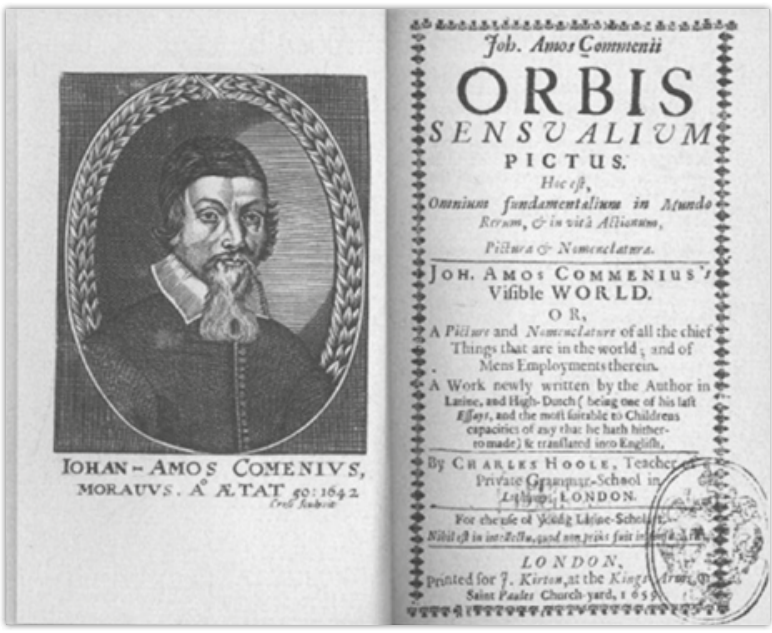

Orbis Sensalium Pictus, 1658

Ahora bien, si miramos en conjunto los principios y procedimientos propios de este método global para la enseñanza de la lectura podemos situarlo, en el clásico análisis de "la querella de los métodos" (Braslavsky, 1962), como núcleo central de los mé- todos de marcha analítica en oposición a los métodos de marcha sintética. Sin embargo, para Braslavsky, lo que constituye la consolidación de este método en el siglo xx tiene una historia cuya antesala principal está contenida en el Orbis Sensalium Pictus, de Comenio, quien sostenía como principio "la palabra asociada a la representación gráfica de lo que ella significa, para que las palabras puedan aprenderse con rapidez, eliminando la 'agobiadora tortura' del 'penoso deletreo'" (Braslavsky, 1962, p. 47).

Siguiendo a la autora, posteriormente, se acogen las experiencias y discusiones del siglo XVIII a través de diversos autores (Nicolás Adams en Francia, Graffunder en Alemania, Wercester en Estados Unidos, Francisco Berra en Argentina, entre otros), lo cual tiene su síntesis en los siguientes principios fundamentales: a) la necesidad de introducir la motivación o el interés de los niños, evitándole esfuerzos penosos (ya sea incorporando ilustraciones o juegos); b) la necesidad de respetar la marcha natural del lenguaje, partiendo de la palabra o la frase tal y como se hace en el origen del lenguaje hablado; c) la necesidad de unir el concepto o la significación a la enseñanza de la lectura; d) la necesidad de tomar como punto de partida la "totalidad" que puede ser la frase o la palabra; e) cierta divergencia acerca de la necesidad de analizar o no esas totalidades; y f) el predominio de la percepción visual en el aprendizaje de la lectura y el desconocimiento de la participación que en el mismo tiene la percepción auditiva, lo que conduce a una fuerte aversión por el método fonético (Cf. Braslavsky, 1962, p. 53-54).

Es importante señalar aquí cómo la obra de Braslavsky se propone hacer una revisión crítica de los métodos hasta ahora más desarrollados y aplicados, especialmente en su recontextualización en América Latina. Así, entre otros análisis, hace una lectura compleja de los postulados de Decroly que incluye algunos de sus libros y artículos publicados, para demostrar cómo el mismo autor no definió de manera taxativa el problema de la descomposición o no de las frases y palabras (procesos de análisis-síntesis) ${ }^{5}$. Para estas

5 Según Braslavsky, incluso hubo contradicciones en los propios postulados de Decroly. Así, por ejemplo, en un texto suyo, que data de 1914, señala: "Nos bastará recordar que el método que empleamos en la aplicación de los principios que son la base de esa psicología, parte de la idea interesante y viva, expresada por la frase y la palabra para llegar, en el momento deseado al análisis, a la sílaba y a la letra y finalmente, por la síntesis, a la reconstrucción de nuevas palabras" (Decroly, citado por Braslavsky, 1962, p. 68). Y en un artículo publicado hacia 1929, insistirá en que la lectura es "una aplicación en el orden perceptivo-visual de la actividad globalizada; en que las palabras y frases deben asociarse a las emociones del niño". Pero, sostiene asimismo que "poco a poco y en la medida de la capacidad del niño, el análisis se favorecerá por la aproximación de las palabras adquiridas ya" (Decroly, citado por Braslavsky, 1962, p. 69). 
autora, más allá de estos principios, el punto de partida indiscutible del método global o ideo-visual y sus variantes es "la palabra", pero la disyuntiva central, entre los autores y las experiencias pedagógicas concretas de aplicación, fue siempre la de enseñar la palabra sin hacer análisis o enseñar la palabra aplicando procesos de análisis y de síntesis.

\section{De la educación nueva a la tecnología educativa}

Hacia mediados de la época de los años setenta en Colombia, de acuerdo con Jiménez y Figueroa (2002), el aparato educativo estatal promovió un debate en torno a la propuesta de la "tecnología educativa", vista en ese entonces como una respuesta innovadora para la transmisión del conocimiento. Siguiendo a los autores, se trataba de una propuesta estadounidense direccionada hacia los países latinoamericanos, que desde una visión de 'desarrollo' exigía la incrementación de procesos tecnológicos en todos los campos, incluyendo la educación, en pro del desarrollo industrial.

En esa coyuntura, los defensores de esta concepción en el campo político señalaban que se requería "de manera urgente elevar la calidad del proceso educacional y el rendimiento de los recursos asignados al sector, expandiendo las posibilidades educacionales" (Jiménez y Figueroa, 2002, p. 159). La tecnología educativa enmarcaba de esta manera "Un conjunto de intentos que pretendían sistematizar el proceso de enseñanza-aprendizaje, mediante la aplicación de un método analítico riguroso y la utilización de aparatos o máquinas que facilitaran la presentación de estímulos en contextos organizados, haciendo más fácil el análisis de las respuestas y la información del retorno consiguiente" (p. 159) ${ }^{6}$.

La propuesta se fundó, grosso modo, con el establecimiento de objetivos específicos para cada área, el diseño de materiales educativos y el uso de programas de instrucción. El papel del 'personal docente' se concibió desde esta perspectiva, bajo la idea de "conducir el medio instruccional, diagnosticar los alumnos, dirigir el uso de los recursos disponibles y coordinar información" (p. 159). Algunos opositores que se pronunciaron frente a esta propuesta señalaron en aquella época la connotación ideológica de la misma - se trataba de una imposición de los Estados Unidos de Norteamérica en el contexto de la Guerra Fría-y el privilegio del saber instrumental por encima del saber humanístico (Cf. Jiménez y Figueroa, 2002, p. 160). Sin

6 Los autores siguen aquí los postulados principales de esta tecnología educativa, a partir de su indagación en la revista Educación hoy, perspectiva latinoamericana, durante 1975 (Cf. Jiménez y Figueroa, 2002). embargo, la pregunta que cabe aquí, en relación con el tema que nos convoca, es precisamente la relación de este enfoque con las concepciones de lectura que agenciaron, su incidencia en los métodos para enseñar y aprender y en los materiales educativos (textos y cartillas) diseñados para este fin.

En esa perspectiva, encontramos que derivado del enfoque de la tecnología educativa surgen precisamente los fundamentos de la concepción conductista de la lectura. Para Goodman (1982), la idea de que la ciencia proveyera todas las soluciones a los problemas educativos coincidió con el surgimiento del conductismo en psicología y del empirismo lógico en filosofía. Específicamente, para el campo de la lectura inicial, este autor refiere cómo William S. Gray desempeñó en Norteamérica un papel decisivo en el desarrollo de una tecnología para su enseñanza, cuyas características se enfocaron en la producción de materiales graduados, la focalización de vocabulario controlado, el desarrollo de una jerarquía de habilidades en las que prima lo fónico y el desarrollo de tests de maduración para predecir el éxito en el aprendizaje, así como tests diagnósticos para medir tal éxito y para determinar las deficiencias (Cf. Goodman, 1998, p. 14-15)

En síntesis, esta tecnología de la lectura se instituyó con estrategias sistemáticas de vocabulario controlado y la ejercitación de una jerarquía de habilidades (skill-drills), con lo que se instituyó una teoría de lectura que vinculó el leer al dominio de una habilidad para "reconocer palabras y adquirir un vocabulario de palabras visualizadas" (Goodman, 1998, p. 15). La oposición a tal enfoque -por lo menos en el plano teórico, en tanto en el terreno de la política estaba instituida la tecnología educativa en Norteamérica - la hicieron investigadores como el mismo Goodman (1982) y Frank Smith (1989) desde la perspectiva psicolingüística, y autoras como Louis Rosenblatt (1978), desde un enfoque transaccional de la lectura, proveniente de los estudios literarios.

\section{El enfoque conductista de la lectura y el método programado}

Una de las evidencias de la asunción del enfoque conductista y de los métodos programados para la enseñanza inicial de la lectura en nuestro país la constituye, sin duda, la investigación comparativa de dos métodos de enseñanza financiada por el Centro de Investigaciones de la Universidad Pedagógica Nacional (Cf. CIUP, Agudelo, R, y Ballesteros, B., 1983). De acuerdo con las autoras, dicha investigación correspondía a la última etapa de una serie de estudios realizados desde 1974 en el campo de la adquisición de las conductas de lectura y escritura. Así, derivado de los hallazgos anteriores 
se realiza la comparación del método programado y del método de palabras normales; este último, de acuerdo con el estudio, el más utilizado y generalizado en las escuelas de la época.

Siguiendo a las autoras, el método programado estaba basado en las técnicas de 'igualación a la muestra' y 'desvanecimiento aditivo y sustractivo', para lograr la generalización de las conductas de lectura a partir de estímulos de discriminación visual de las formas (muestras y resaltados en colores) y de carácter social, tales como felicitaciones o premios. Agudelo y Ballesteros (1983) recurren en su revisión bibliográfica a diversos estudios que favorecen tales técnicas descritas, derivados de la Journal of Experimental Analysis of Behavior, lo cual sitúa directamente la concepción de lectura agenciada en tanto 'conducta' resultado del aprendizaje sin error y aplicación sistemática de estímulos, provenientes, en efecto, de la psicología conductista.



Ejemplos de Igualación a la muestra y pruebas de discriminación visual (Agudelo y Ballesteros, 1983)

Siguiendo a las autoras, el método programado comprendía las siguientes unidades y procedimientos:

Las cinco primeras corresponden a la lectura y escritura de vocales, las 42 restantes incluyen en su orden: lectura de una palabra básica (en la cual se introduce el elemento nuevo, ejemplo: mamá, coco), lectura de la sílaba básica (elementos nuevos más la vocal correspondiente, ejemplo: ma, co, lectura del sonido de la consonante nueva, ejemplo: $\mathrm{m}, \mathrm{c}$, excepto en las unidades correspondientes a las combinaciones); escritura de la consonante, la sílaba y la palabra básica; lectura y escritura de las sílabas directas restantes (consonante más demás vocales), lectura y escritura de palabras auxiliares (formadas por sílabas conocidas) y lectura y escritura de una frase (excepto en la unidad seis). (Agudelo y Ballesteros, 1983, p. 12-13)7.

En contraste, el método de palabras normales no tenía un procedimiento único, pues estos dependían de los criterios específicos de cada maestro. Sin embargo, a partir de una revisión de literatura, las conversaciones con maestros y la observación de clases, Agudelo y Ballesteros destacan dentro de esta metodología: 1) la expresión oral sobre el dibujo que representa la palabra que se va a enseñar; 2) la presentación de la palabra escrita resaltando en colores la nueva letra; 3) la lectura, primero la maestra, luego los niños en forma individual o en coro; 4) la escritura de la palabra, con movimientos de la mano en el aire, en el pupitre, en el tablero, en plastilina, etc.; 5) el análisis de la palabra dividiéndola en sílabas y luego en letras; 6) la síntesis de la palabra, de la letra a la sílaba y de ahí a la palabra; 7) la formación de sílabas directas; 8) la formación de palabras auxiliares con sílabas conocidas; 9) la formación de una frase sencilla; 10) ejercicios adicionales de lectura de la palabra en varias posiciones, tamaños y contextos; 11) la aplicación de correctivos, que incluyen planas adicionales a quienes no aprenden los elementos enseñados (Cf. Agudelo y Ballesteros, 1983, p. 14-15).

Si bien los resultados del estudio no mostraron diferencias lo suficientemente significativas en las variables de adquisición y mantenimiento entre los dos métodos, sí develaron ventajas en algunos aspectos concretos de uno y otro ${ }^{8}$. Para el caso de la

7 Se ha de señalar que, de acuerdo con las autoras, este método implica que en cada sesión de clase solo se introduzca una unidad y no se pase a la siguiente si la anterior no se ha adquirido totalmente, así: "En caso de respuestas incorrectas en las pruebas de adquisición y/o mantenimiento, se utilizarán como correctivos un repaso del material correspondiente y planas controladas de aproximadamente 10 ejecuciones". (Cf. Agudelo y Ballesteros, 1983, p. 12-13)

8 Proveniente de la metodologías propias del análisis experimental de la conducta, el estudio referenciado recurre a la construcción de hipótesis y variables - dependientes (elementos del programa, tiempo de aprendizaje, secuenciación de los elementos, ambiente físico, experimentador, etc.) e independientes (el método)También realiza tests de entrada y análisis de resultados a partir de la contabilización de las respuestas correctas (adquisición de sílabas, palabras auxiliares y posterior generalización de la conducta de lectura) a través de una prueba t y prueba de cola (Cf. Agudelo y Ballesteros, 1983, p. 17-43). 
generalización, las autoras destacan la favorabilidad de actividades que se realizaron con el método de palabras normales: la imitación de la forma de la palabra normal con el dedo, con la mano, en el aire, en el pupitre o en el piso y la enseñanza de las sílabas con la repetición oral por parte del alumno. Por su parte, el método programado permitió el control de la respuesta activa por parte del alumno, en tanto cada uno tenía su propio material, lo cual, según las autoras, favorecería la formación de hábitos de estudio a la manera de lo propuesto por Speller (1978) ${ }^{9}$; asimismo, el uso de monitorías por parte de alumnos adelantados para apoyar la aplicación de correctivos y la optimización del tiempo para el profesor (Cf. 1983, p. 46-48).

\section{El procedimiento combinado y el método de palabras normales:}

No obstante, la institucionalización de la tecnología educativa en Colombia durante la década de los setenta e inicios de la década de los ochenta, los métodos programados no alcanzaron a generalizarse en las prácticas escolares de enseñanza inicial de la lectura. Tanto en el estudio de Agudelo y Ballesteros (1983) como en la descripción sobre los métodos de lectura que ofrece Fandiño (1985), se constata que el método de palabras normales fue el de mayor aplicación en nuestras escuelas; si bien todo confirma la impresión de que éste era muy similar en su estructura a los métodos programados y, de ahí, que se ajustara a los diseños instruccionales de la época.

Descrito como se hizo en el acápite anterior, el método de palabras normales combina procedimientos de análisis y de síntesis, partiendo de una palabra y su descomposición en sílabas y letras, para luego recomponerla de nuevo hasta llegar a la formación de oraciones que la contengan. Cada unidad de trabajo implica volver sobre la palabra, sílaba y letra trabajadas con anterioridad, para adicionar posteriormente un nuevo elemento. Algunos autores, como Uhía Pinilla (1988), identificaron este procedimiento combinado como una resultante del método ideo-visual y el de palabras normales, que vendría a resolver el conflicto entre métodos de marcha sintética (fonéticos, silábicos o alfabéticos) frente a métodos de marcha analítica (global o ideo-visual). Precisamente, este autor propondrá partir de "palabras generadoras" que conformen ideas totales, pero que contengan las

9 Este autor se reconoce como el creador del Sistema de Instrucción Personalizada (SIP), cuyo modelo fue reproducido inicialmente en Brasil y luego transferido a otros países de América Latina, en lo que se conoció como el modelo de la tecnología educativa. El lema "Good by teacher" fue el promovido por este sistema. letras determinantes que han de apoyar el aprendizaje (Cf. Uhía, 1988, p. 67) ${ }^{10}$.

Ahora bien, tanto el procedimiento combinado como el método de palabras normales suponen y exigen el desarrollo de unos ejercicios previos a la enseñanza de la lectura y la escritura, en simultáneo, denominados "aprestamiento". Uhía (1989) identifica este tipo de ejercicios en una línea más amplia, que excede la sola preparación para la lectura y la escritura y busca, además, la adaptación del niño al nuevo ambiente escolarizado, la identificación de sus capacidades y características individuales y el desarrollo de actividades gratas e interesantes que permitan generar la motivación y el interés hacia el aprendizaje. El aprestamiento comprende así, desde las conversaciones sobre temas que interesen a los niños y la visita a sitios naturales e históricos de la localidad hasta la narración de cuentos, entre otros (Cf. p. 33-43) ${ }^{11}$.

En todo caso, en este contexto el aprestamiento se constituyó en un programa previo que hacía énfasis en el desarrollo sensoperceptivo como preparación a la lectura, pero superando la concepción asociacionista para adentrarse en la construcción de nociones más complejas en el niño como la del espacio y el tiempo, la comprensión de su lateralidad, así como el desarrollo de destrezas motoras pensadas en función de la escritura manual, con el lápiz o el lapicero.

Sin embargo, autoras como Villega Robles en Colombia (1996) ubican, tanto los procedimientos del método global como del método de palabras normales, así como las actividades previas de aprestamiento, con el enfoque perceptivo-motor de la lectura, ajustándose ambos a las concepciones conductistas sobre su enseñanza y su aprendizaje ${ }^{12}$. Y mucho antes de que

10 Dentro de las características que suponen el uso y la efectividad de un método combinado - llámese de palabra normal o palabra generadora-, Uhía sostiene que las palabras deben prestar en primera instancia especial atención a las vocales, puesto que constituyen las letras determinantes básicas, gráfica y fonéticamente, que sustentan además la formación de las palabras (Cf. Uhía, 1998, p.70-71).

11 Es en este marco de desarrollo sensoperceptivo que se propone como parte del aprestamiento actividades que le permitan al niño reconocer diferentes formas, colores, tamaños y sonidos (discriminación visual y auditiva); desarrollar su coordinación visomotora a través del uso de materiales para la escritura y ejercicios de direccionalidad, de construcción de secuencias, así como de recortado, rasgado, picado, plegado, entre otras (Cf. Uhía, 1988, p. 97-122). Para el caso del esquema corporal, además de la identificación de su propio cuerpo se propone el desarrollo de la lateralidad y de las nociones espacio-temporales en el niño.

12 En su libro Escuela y lengua escrita, Villegas Robles (1996) interpelará estos enfoques y sus métodos materializados en las cartillas escolares de la época, con un amplio estudio en el que antepone la psicogénesis de la lengua escrita y las propuestas constructivistas para su aprendizaje. Sobre ello volveremos más adelante al abordar tal enfoque constructivista. 
empezaran a aparecer estas interpelaciones en nuestro país, la ya clásica investigación de Emilia Ferreiro y Ana Teberosky (1979) interrogará estos métodos, sean fónicos o sintéticos, con preeminencia de lo auditivo, o globales o analíticos, con preeminencia visual, por considerarlos, en su conjunto, contraproducentes frente los intentos de los niños por comprender y apropiar el sistema de escritura. Mediante un estudio cuya base se asentó en la perspectiva psicogenética piagetiana, estas dos autoras determinarán las hipótesis lingüísticas de los niños en este proceso de adquisición, y consolidan así un novedoso enfoque de aprendizaje que problematiza las prácticas de enseñanza instituidas con los métodos referenciados. Esto es lo que denominamos a continuación enfoque constructivista.

\section{El enfoque constructivista en la lectura y el proceso de construcción de la lengua escrita}

Particularmente, en el área de Lenguaje, los métodos tradicionales de enseñanza de la lectura con enfoque perceptivo-motor, herederos de la concepción conductista, también empezaron a ser problematizados en el país a partir de la "Propuesta curricular piloto para el grado cero" y el documento de marco político, conceptual y pedagógico en el que se apoyó dicha propuesta (MEN, 1992).

En este se introduce un capítulo acerca de "La construcción de la lengua escrita en el Grado Cero" (Cf. Jaramillo y Negret, 1992), que en contraposición al enfoque dominante en la alfabetización inicial, propuso una concepción de lectura y escritura desde una perspectiva psicogenética y sociocultural del desarrollo del lenguaje escrito en los niños. Es así como Jaramillo y Negret, apoyándose en las teorías e investigaciones de Ferreiro, Teberosky y Tolchinsky, realizan una propuesta pedagógica que comprende tres ejes fundamentales: a) la promoción de la expresión, fundada en el desarrollo de las capacidades expresivas del niño y buscando que el maestro posibilitara dicha expresión a partir de las vivencias de los niños y la combinación de la expresión gráfica y grafológica; b) la producción y circulación de los textos escritos, asumiendo por producción toda acción que realiza el sujeto con la lengua escrita, bien para producir textos escritos o bien para interpretar los ya producidos; y c) el contacto y contrastación permanente con las producciones escritas de la cultura, lo que implicaba, a su vez, la contrastación de las producciones mismas de los niños sin importar las diferencias, la contrastación con las producciones escritas de las maestras y las contrastaciones formales para enseñar aspectos puntuales del quehacer escritural (Cf. p. 42-43).
En síntesis, la concepción que se defiende allí se funda en la idea de que el niño construye sistemas de escrituras no convencionales que significan por sí mismos, y que, poco a poco, en confrontación y en desarrollo de sus propias hipótesis, van configurando la convención grafemática y alfabética propia de nuestra lengua. Tales aseveraciones, corresponden efectivamente a la perspectiva psicogenética de la escritura (Ferreiro y Teberosky, 1989).

Por otra parte, pero en esa misma línea renovadora de los enfoques pedagógicos para enseñar a leer es importante destacar para la época la realización del Seminario-Taller del área de Español y Literatura (1992), al que asistieron algunos maestros e investigadores, así como profesionales del área de los Centros Experimentales Piloto. De acuerdo con De Castro, Pérez, Rodríguez, Rincón y Bustamante (1994), a partir de las discusiones desarrolladas durante este seminario, así como los comentarios escritos remitidos desde las diferentes regiones, se redactó un documento para abrir el debate nacional sobre la enseñanza de la lengua escrita y de la lectura desde preescolar hasta tercer grado. En la introducción a dicho documento se plantea que

\begin{abstract}
El sistema educativo se encuentra frente al reto de cambiar sus modelos, así como las prácticas y actitudes de los docentes, padres de familia y la comunidad educativa en general. [...] Es necesario desarrollar la capacidad de respetar, valorar y apoyar los esfuerzos de los niños por llegar a sus propias elaboraciones conceptuales, sin que la intervención del adulto se limite a calificarlas de "buenas" o "malas" o a imponer su saber, sin tener en cuenta los procesos de intelección del niño. Dentro de esa perspectiva son fundamentales planteamientos como los de Piaget, Vygotsky, Luria, Bruner, Teberosky y Ferreiro, donde el lenguaje, y la lengua escrita en particular, son determinantes en los procesos de construcción de saberes (competencias cognoscitivas, valorativas, etc.) y de desarrollo de habilidades (desempeño con objetos, personas y significados). (De Castro et al., 1994, p. 7-8)
\end{abstract}

De esta manera, la concepción de base, al igual que en la Propuesta para el Grado Cero, proviene de teorías y autores diversos, que se han identificado en la educación como parte del enfoque constructivista. La idea del niño como sujeto activo, que pone a prueba hipótesis sobre el mundo que lo rodea, lleva a muchos de estos autores a formular que "antes de llegar a la escuela, él construye conocimiento sobre la lengua escrita, independientemente de una intervención sistemática de enseñanza" (p. 26).

Estas investigaciones, siguiendo el mismo documento, permiten dar cuenta del proceso de construc- 
ción del sistema de escritura antes y durante la escolaridad y de las estructuras cognoscitivas que construye el niño en el proceso. Por lo tanto, las premisas pedagógicas implican comprender que: "Leer no es descifrar, sino construir sentido a partir de signos gráficos y de los esquemas de pensamiento del lector; escribir no es copiar, sino producir sentido por medio de los signos gráficos y de los esquemas de pensamiento de quien escribe; la lectura y la escritura no se restringen al espacio escolar" (De Castro et al., 1994, p. 27).

Para el caso específico de la lectura, que de acuerdo con esta perspectiva no se separa de la construcción de la lengua escrita por parte de los niños, los autores señalan la necesidad de hacer una revisión "tanto conceptual como de las prácticas escolares que se han utilizado en su enseñanza y que la han convertido en un acto mecánico, de descodificación, de reproducción oral de los signos escritos, reduciendo la compresión solo a la recuperación memorística de la información de un texto" (p. 46) ${ }^{13}$.

De esta manera, hacer énfasis en el descifrado o hacer depender las experiencias de la lectura del dominio de la información grafo-fonética, tal y como se hace a través de los métodos de lectura más instituidos y descritos en acápites anteriores, puede resultar contraproducente. En contraposición se señala: "Se trata más bien, de propiciar el acercamiento a los textos escritos y crear la necesidad de leerlos anticipando y prediciendo su contenido a partir de los índices, de las marcas gráficas o lingüísticas, del portador de texto, del contexto en que aparece" (p. 47). Tal concepción para la enseñanza de la lectura recoge también los planteamientos provenientes de la psicolingüística (Goodman, 1982; Smith, 1989), en los cuales leer está ligado directamente a la comprensión y supone la activación de estrategias - de muestreo, predicción, inferencia, validación y autocorrección-que modifican la interpretación de lo que se lee y permiten anticiparse al texto. Finalmente, al decir de los autores:

Cuando se lee con el propósito de producir sentido, es decir, cuando el lector tiene unos objetivos definidos (por ejemplo, buscar información, o recreación), existe más posibilidad de que todas estas estrategias se pongan en práctica y se realicen predicciones e inferencias más certeras. El uso de estas estrategias lleva a producir sustituciones, reemplazos, omisiones, paráfrasis, vacilaciones, que,

13 En concreto, para comprender este proceso de construcción de la lengua escrita, los autores del documento desarrollan conceptualmente los tres períodos que, siguiendo a Ferreiro (1988), pueden distinguirse en esa construcción del niño: a) distinción entre los modos icónicos y no-icónicos de representación; b) construcción de formas de diferenciación; y c) fonetización de la escritura. (De Castro et al., 1994, p. 27-28) desafortunadamente, se consideran patologías en la escuela. Por esto, cuando ellas se presentan el maestro constantemente interrumpe a los niños durante sus lecturas, exige descodificar, regaña, y hace perder el sentido y el interés. Un hecho más grave aún es que esta situación los conduce a dejar de lado los esfuerzos por establecer un diálogo con el texto, único camino posible para cuestionarlo (tener un acercamiento critico), transformar los esquemas del lector (enriquecer los conocimientos y establecer nuevas relaciones inter-textuales) y generar nuevas preguntas y textos (trascender el texto y acercarse a otros). (De Castro et al., 1994, p. 48-49).

Estos planteamientos sobre la lectura y la lengua escrita suponen una ruptura con los enfoques conductistas y, en general, con los métodos para la enseñanza inicial de la lectura, sean estos de corte sintético o analítico; aunque podríamos decir que están más cerca de éstos últimos, especialmente en consonancia con algunos de los principios del método global y de la pedagogía activa decrolyana. No obstante, supera los planteamientos allí esbozados sobre la lectura, pues se trasciende su énfasis perceptivo-visual y se asume en perspectiva cognitiva, comunicativa y textual.

¿Cuál sería entonces el lugar de las cartillas y textos escolares para la enseñanza inicial de la lectura a partir de este enfoque? La respuesta la podemos hallar en los trabajos de Kenneth y Yetta Goodman, pioneros de esta perspectiva constructivista e integral de la lengua en Norteamérica, que como se observa tuvieron gran influencia en el marco del debate pedagógico en Colombia. Especialmente, Yetta Goodman, en su análisis sobre el conocimiento del niño y las raíces de la alfabetización, elabora una conclusión que, a nuestro modo de ver, responde ampliamente el interrogante: "Las actividades de aprestamiento, las cartillas y los libros de texto ignoran las experiencias que los niños tienen de la lectura y escritura antes de la escuela y los tratan como botellas vacías" (1991, p. 7).

\section{Los textos escolares para enseñar a leer y la industria editorial}

Los textos escolares, es decir, aquellos libros pensados, diseñados y producidos específicamente para su uso en la enseñanza, constituyen una materialidad vinculada directamente a la industria editorial. En ese sentido, no son solo un recurso didáctico y pedagógico usado por los maestros en las escuelas, sino que también adquieren el carácter de mercancía: la finalidad última es su posterior difusión para el consumo y la venta. De acuerdo con Bonafé (2008), no es posible estudiar los libros de texto de manera 
aséptica o meramente pedagógica, desconociendo este carácter económico que moviliza la industria editorial, máxime si se reconoce que en los ámbitos institucionales de la escolarización, este tipo de libros son una forma dominante de presentación y concreción del currículo en las escuelas.

Para este autor, el uso activo del libro tendría que pensarse a partir de una teoría del trabajo, de la formación y del conocimiento práctico del docente, en concreción directa con un conjunto de relaciones estructurales y estructurantes entre el saber y el poder. Y si bien nuestra investigación no se detiene en estos usos activos y por tanto no se ocupa en especial de este carácter de mercancía, sí se ha de reconocer este tipo de relaciones económicas subyacentes a la industria editorial y a la producción, circulación y consumo de este tipo de libros ${ }^{14}$. De esta manera, en ese ir tras las huellas de los enfoques y métodos para la enseñanza inicial de la lectura en las cartillas o textos escolares ${ }^{15}$, necesariamente nos situamos frente al papel de las editoriales en el país, que dedicaron una producción bastante amplia en este campo.

Así, se puede reconocer inicialmente a la editorial Voluntad como una de las primeras empresas que desde 1928 se dedicó a la impresión de estos primeros textos escolares, resentando además ventas sin precedentes con la cartilla Alegría de leer en sus años de vigencia ${ }^{16}$ o reeditando y transformando otra clásica cartilla como la de Justo Charry (1918). Esta

14 En nuestras indagaciones sobre este lugar de la industria editorial en el libro de texto, encontramos que dicha producción es, en efecto, una actividad de carácter comercial, pero exige necesariamente un trabajo de planificación coordinado por un editor hacia autores, diseñadores e ilustradores. La tendencia dominante en la consolidación de estos equipos es integrar a maestros en ejercicio, a especialistas en las áreas y a pedagogos o psicopedagogos que orientan la producción en términos pedagógicos y didácticos. No obstante, el carácter de mercancía que comporta el texto escolar hace que las leyes del mercado más que el conocimiento y la investigación pedagógica sean determinantes a la hora de comercializar el producto.

15 Con estas denominaciones (cartilla, libro de lectura o texto escolar) aludimos en su conjunto a aquellos libros diseñados con la intención expresa de dirigir los procesos de enseñanza y aprendizaje en el aula, y, particularmente, para ser usados con los niños. Algunos investigadores se han centrado en el estudio histórico de este tipo de libros, diferenciando incluso sus nominaciones (Cf. Escolano, Ossenbach, Choppin,). En Colombia, estudios de esta misma naturaleza (Cf. Quiceno, 2001) permiten comprender la diferencia expresa entre "manual" y "texto escolar". Esta última denominación que se generaliza para este tipo de libros.

16 De acuerdo con Jorge Orlando Melo (1999), Alegría de leer fue el libro colombiano más vendido en Colombia, antes que las obras de García Márquez, y cada uno de sus tomos superaron el millón de ejemplares, lo que constituye un indicativo de su nivel de influencia en el modo como aprendieron a leer los colombianos. última, que en su edición de los años setenta aparecerá reformada y actualizada bajo el título Nueva Cartilla Charry, suscribiéndose desde su prólogo al método ideo-visual o global. En paralelo a estas publicaciones, la editorial Susaeta también aparece en la escena con la cartilla Coquito (Everardo Zapato, 1955), la cual desde entonces, según Herrera Casilimas (s.f.), ha sido reeditada y adecuada con nuevas orientaciones de la lectura y continúa vigente en la actualidad.

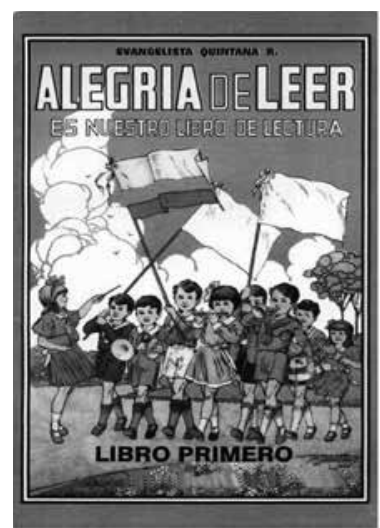

Cartilla Alegría de Leer

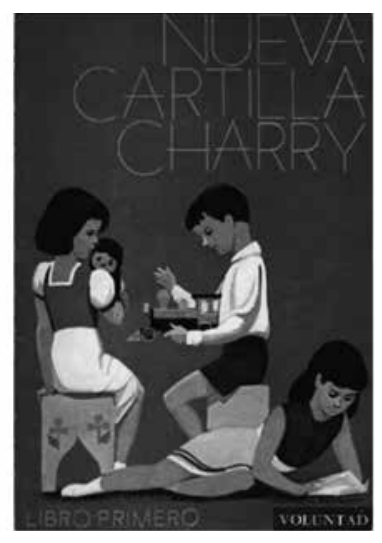

Nueva Cartilla Charry
Pero quizás otro caso representativo de cartillas que se popularizaron tanto como las anteriores lo constituye Nacho, libro inicial de lectura, editado inicialmente en 1972 también por Susaeta y reeditado en los años ochenta bajo la coordinación editorial de Jorge Luis Osorio Quijano. Este texto, sin duda, constituye todo un ejemplo paradigmático de reintroducción del método de palabras normales" ${ }^{17}$, y desplaza de nuevo la concepción ideo-visual y globalizante de las cartillas que como la Nueva Charry o Sonata se ajustaron a estos principios y circularon en la década de los setenta.

Es importante destacar cómo en estas últimas, prevalecen en cada unidad las narrativas icónicas - escenas que ilustran una situación (con personas, animales u objetos) que puede ser descrita- de las cuales se extractan, inicialmente, sustantivos con sus respectivos artículos o pronombres hasta complejizar las mismas expresiones y dotarlas de contenido proposicional. La secuencia se repite tanto en Sonata como la Nueva Charry y, posteriormente, se procede a la identificación explícita de las unidades grafemáticas de nuestro sistema alfabético.

17 De acuerdo con el estudio de Rincón, B. (2003), el método de palabras normales aparece ya planteado en el libro Elementos de Pedagogía, de Martín Restrepo Mejía, que integra la inducción y la deducción del código a partir de palabras comunes (p. 147). 



Cartilla Sonata (1971)

En contraste, la popular Nacho de los años ochenta introduce como mecanismo de las lección el siguiente: "1으 La palabra normal, con su respectiva ilustración. $2^{\circ}$ Lista de doce palabras, en tipo de imprenta y tres columnas. $3^{\circ}$ Palabras, con su respectiva figura. $4^{\circ}$ Cinco frases u oraciones. $5^{\circ}$ Un pequeño texto, con sentido unitario, en cuyas palabras figuran combinaciones silábicas de la lección correspondiente y las anteriormente aprendidas"18.
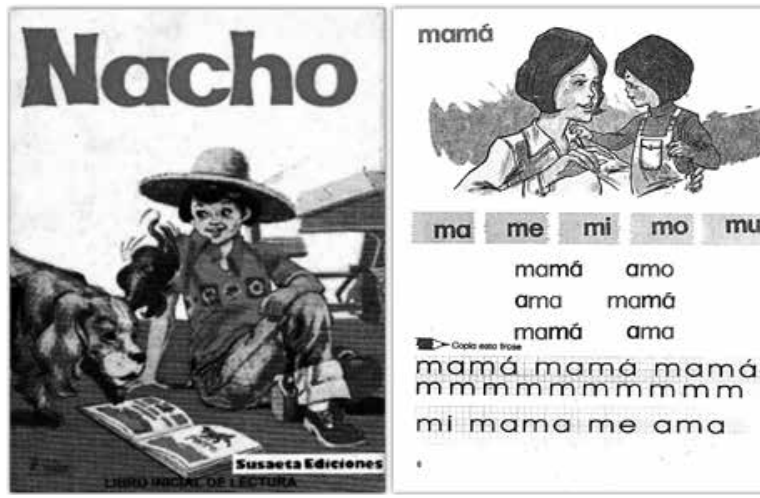

mamá mamá mamá $\mathrm{mmmmmmmm}$ mi mama me ama

Cartilla Nacho (1984)

Ahora bien, para esta misma década de los ochenta y también entrado los noventa aparecerán una variedad de textos de muchas otras editoriales (Libros\&Libres, Norma, Educar Editores, El Cid, Santillana, etc.), que vendrán a competir con nuevos formatos, ilustraciones y presentaciones didácticas dirigidas a los maestros. Sin embargo, la revisión global de una muestra de este tipo de textos nos permite

18 Extraído de la Guía didáctica para la enseñanza de la lectura y la escritura. Ediciones Susaeta. Para el desarrollo del proceso en el aula se recomienda a partir de un ejemplo (la palabra normal "mamá) lo siguiente: 1. Conversar sobre la mamá (cuento). 2. Presentar la lámina de la mamá. 3. Lectura del vocablo "mamá", en tipo imprenta. 4. Lectura de aplicación con palabras nuevas: mía, amo, mima. 5. Lectura de aplicación con frases, oraciones y trozos: mamá mía, mi mamá me ama, amo a mi mamá. deducir que los cambios en cuanto a la introducción del código escrito en los niños son adjetivos, en tanto se mantiene como constante no solo el inicio con la palabra normal "mamá", sino también el método en cuanto a su estructura y secuencia: una introducción de las vocales, luego las consonantes y, posteriormente, las combinaciones. La variante la constituye la presentación por vía analítica, es decir, partiendo de relatos, oraciones o palabras, o, por vía sintética, destacándose la letra (mayúscula/minúscula-script/ cursiva) y las sílabas, para llegar a la conformación de palabras.



Armonía del lenguaje (1984)

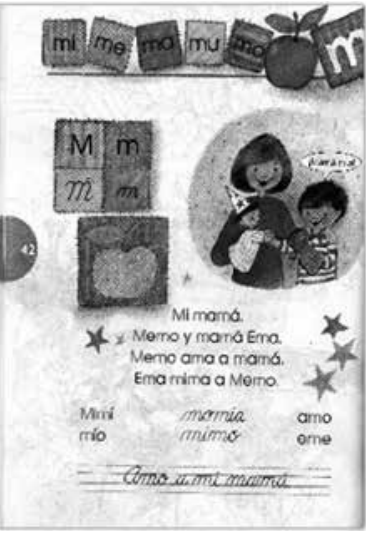

Trampolín (1987)

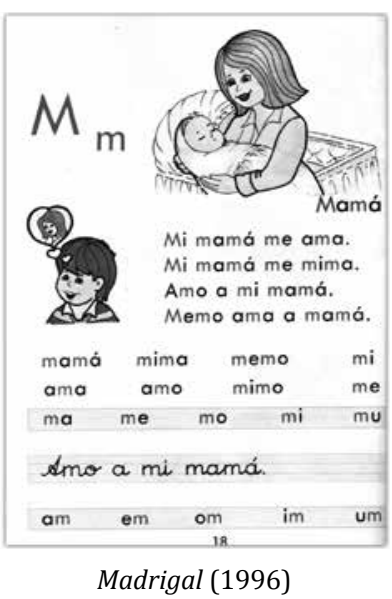

Por otra parte, en estas dos décadas de los ochenta y noventa, sí es posible advertir algunos cambios sustantivos en cuanto a los diseños - tamaños, colores, técnica en las ilustraciones, número de páginas, etc.- e integración de actividades de trabajo con los niños dentro del mismo texto escolar. Así, además del 'aprestamiento', que tiene preeminencia en los noventa, también aparecen en algunos de estos textos actividades de lectura y de escritura, que se sugieren para ser desarrolladas por los niños en el libro de texto $o$ en el cuaderno, de manera individual o en grupo, 
como actividad en clase o para la casa, e, incluso, para ser desarrolladas con la familia ${ }^{19}$.

Si bien estos cambios en la materialidad o formato físico del texto obedecen en un primer momento a un asunto de condiciones técnicas e industriales de cada casa editorial, también tienen que ver con decisiones de orden comercial en las que las relaciones entre oferta y demanda son definitivas. No es gratuito entonces que en nuestra revisión halláramos por ejemplo dos libros de texto o cartillas de la misma casa editorial, análogas en su estructura inicial del método, pero diametralmente distintas tanto en la calidad del papel como en el número de hojas adicionadas para otro tipo de actividades, contenidos y lecturas: uno ofertado a los colegios privados y el otro para los niños y familias de instituciones del sector público ${ }^{20}$.

Este insumo del libro - el papel y su calidad - es determinante en el costo de producción. Pero ¿qué reduce un libro de texto al suprimir páginas? Reduce contenidos, lecturas y actividades que pueden ser realizadas con los niños. Es decir, la reducción sobre los costos de producción y, por tanto, en el precio de venta, es también de orden simbólico y cultural, lo cual por esta vía se redistribuye de nuevo inequitativamente.

En cuanto a la amplia producción editorial de los años noventa, es necesario anotar finalmente que si bien en términos generales los textos escolares mantienen el mismo método - pese a que la reforma curricular de 1984 ha sido reemplazada para la época a partir de la Ley General de Educación (1994) y los nuevos Lineamientos Curriculares de Lenguaje (1998)—, la importancia en ventas de la cartilla Nacho es relevante, asunto que se mantiene incluso en la actualidad ${ }^{21}$.

En síntesis, podríamos agregar que determinados por los costos de producción y por las leyes del

19 Eventualmente, algunos de estos textos incluían temáticas propias del área de Español y Literatura para primer grado (los nombres, las cualidades y las acciones, los medios de comunicación, los oficios y las profesiones, entre otros) estipuladas en los programas curriculares de la época.

20 El ejemplo concreto de esta situación es la cartilla Festival, ofertada a los colegios de carácter privado, que tiene su correlato bajo el título Alborada, diseñada para el consumo de las familias y niños del sector oficial. La primera se explaya en una estética de la ilustración y en un conjunto de actividades que pueden ser realizadas con los niños en el mismo libro y que incluyen hasta una antología literaria. La segunda es reducida a una cartilla, sin los anteriores elementos, donde el método hace las veces de libro de lectura y método de enseñanza.

21 En su página web, Susaeta estipula hoy el precio de Nacho reeditado en 8.000 pesos. Asimismo, refieren que por lo menos 20 millones de niños en países como Ecuador, Panamá, Colombia, Venezuela y República Dominica han aprendido a leer con ella, lo cual sugiere su potencial en ventas y usos activos (Cf. http://www.susaeta.com.co/producto/silabario/nacho-libroinicial-de-lectura/1). mercado, los libros de texto no operan solo como difusores de cultura para todos, como canal de materialización de las reformas educativas o como materiales curriculares para la escuela. Operan definitivamente como una instancia mediadora entre el saber/poder y las relaciones de clase. Como bien lo señala Bonafé y lo reitera Escolano, si los textos son el resultado de numerosos agentes y agencias, no se nos puede olvidar "que al abrir sus páginas permitimos simultáneamente que diversos poderes, como los mediáticos o los financieros, condicionen nuestro acceso a la Cultura" (Escolano, 1998, p. 3.)

\section{La enseñanza de la lectura en el discurso pedagógico oficial}

Es evidente que toda enseñanza, en sus enfoques y métodos, está influenciada en menor o en mayor medida por la política pública y la regulación que desde allí se ejerce, tanto en el currículo como en los procesos de enseñanza y aprendizaje. Ahora bien, situado como está el presente estudio en una época que constituye gran parte del proceso de modernización de la escuela en Colombia, lo primero que debemos anotar es la sujeción de la política educativa a las propuestas de desarrollo que se derivaron de los organismos multilaterales y del proceso de mundialización de la educación. De ahí que, de acuerdo Martínez, Noguera y Castro (2003), el país se comprometiera desde la década de los sesenta con un modelo educativo cuyo propósito general fue "la escolarización y curricularización masiva de la población, en la perspectiva de lograr las metas planteadas por la nueva estrategia de desarrollo" (p. 104).

Frente a lo que se denominó la 'crisis mundial de la educación', la salida se forjó mediante la transferencia y difusión de componentes tecnológicos al campo educativo. Se emprende entonces un gran proyecto de diseño curricular y perfeccionamiento docente que se instaló en los principios del diseño instruccional y la tecnología educativa. Así que tales principios constituyen, inicialmente, la perspectiva desde donde se posiciona el discurso oficial en la enseñanza de la lectura, pero que luego empezará a transformarse como efecto de otros enfoques teóricos y pedagógicos que fueron emergiendo y que se describieron anteriormente. Un breve recuento de dichas transformaciones se describe en lo que sigue.

\section{La prescripción oficial: el método global en la lógica de la tecnología educativa}

Con la intención de iniciar este proceso de curricularización de la enseñanza en el país se emite en 1963 el 
Decreto 1710, que define los objetivos de la educación primaria. Unido a este se firma el primer convenio bilateral con el gobierno alemán -la denominada Misión Pedagógica Alemana-, cuyo propósito fue actualizar los programas que se venían implementando desde 1950 y contribuir al desarrollo de los programas emitidos en virtud del mismo decreto. Martínez et al. (2003) señalan que este trabajo se realizó a través de tres estrategias: la elaboración de guías para el desarrollo de nuevos planes de estudio, el diseño de material didáctico para auxiliar al maestro en su práctica de enseñanza y la capacitación del maestro en el uso de las guías y del material didáctico elaborado.

Es así como en las primeras Guías para el maestro (1969) encontramos tres volúmenes (desarrollo, parcelación y anexo) que realizan efectivamente prescripciones curriculares a los profesores de primero hasta tercer grado. El volumen Parcelación, que contiene la distribución semanal de los temas de estudio. El volumen de Desarrollo, que presenta actividades básicas para desarrollar el programa de cada grado, desde una perspectiva globalizada; y, finalmente, los nominados Anexos, con las indicaciones metodológicas y los contenidos para considerar en la labor docente. No obstante, llama la atención que estas guías, más que introducir una lógica vinculada con un enfoque instruccional de la lectura, plantean una propuesta que se basa en la noción de integralidad curricular y de enseñanza global. La apuesta pedagógica se instala en los principios de la escuela activa, sobre todo en su noción globalizadora. Así, atendiendo a esta idea, en la Guía para el maestro de primero de primaria, se afirma que el programa del grado se parceló, teniendo en cuenta las características de aprendizaje que presenta el niño de 7 a 8 años:

En esta edad el pensamiento del niño es global; el preescolar capta fácilmente conjuntos y manifiesta dificultades en la percepción y observación de los detalles. Como consecuencia, los conocimientos deben presentarse de forma integrada, para que las experiencias no pierdan el sentido que las vitaliza y para que los objetivos de cada actividad sean comprendidos y asimilados por los escolares. (MEN, 1969)

Se argumenta además que se adopta el método global por considerarlo el más adecuado para "realizar en forma natural la transición de las actividades familiares a las escolares y lograr los propósitos asignados para el primer grado" (MEN, 1969). En consonancia, se sugiere poner al niño en contacto directo con una mecánica de la lectura, a través de la visualización e identificación de un vocabulario de base. Allí se destaca, por ejemplo, el tipo de ejercicios propuestos a los maestros:
Colocar los nombres de los objetos del salón en cartones pequeños. Asociar el signo escrito con la pronunciación. Rotular los puestos de los niños con el respectivo nombre (en este momento el niño debe comenzar a coleccionar las palabras dentro de su caja de vocabulario). Identificar palabras relacionándolas con un dibujo. (MEN, 1969, p. 23)

De ahí que en esta revisión general se pueda concluir que, más allá de una implementación absoluta de la tecnología educativa, a finales de la década del sesenta y en los comienzos de los años setenta, opera más bien una coexistencia entre el enfoque de la lectura que retoma planteamientos de la nueva educación y promueve el método global y unas estrategias metodológicas de planeación, desarrollo y evaluación, que poco a poco fueron introduciendo el discurso instruccional y el enfoque conductista en la enseñanza de la lectura.

\section{La renovación curricular: entre el enfoque conductista y el enfoque semántico-comunicativo}

La década de los ochenta marcó un hito importante en el campo de las reformas educativas en Colombia. A partir de 1976, en el contexto de la nacionalización de la educación primaria y secundaria, se da inició a la denominada "Renovación curricular" mediante el Decreto 088 de ese mismo año. Propuesta impulsada desde el Ministerio de Educación Nacional cuyos propósitos centrales fueron: diseñar por áreas los currículos de la educación básica y secundaria, media vocacional e intermedia profesional; proponer los currículos para la capacitación y perfeccionamiento docente; y, por último, elaborar los programas por áreas en contenidos progresivamente graduados.

Ahora bien, dicha renovación generó en la época importantes discusiones, tanto en su etapa de diseño como en su implementación. Una de estas tuvo que ver con la connotación asignada a la tecnología educativa en el proceso, y específicamente se dio en la construcción de los Marcos Generales del Currículo ${ }^{22}$. La segunda discusión, que además se constituyó en un punto de quiebre de la Renovación curricular,

\footnotetext{
22 Una primera versión de estos Marcos fue emitida en 1977, otra posterior en 1981, teniendo como asesor principal a Carlos Federicci y, una tercera y cuarta versión publicada en 1982, bajo la coordinación de Carlos Eduardo Vasco. El cambio de asesor, de acuerdo con Arboleda (1986), suscitó un debate con respecto al lugar que se le estaba atribuyendo al diseño instruccional en la elaboración de los programas. Este investigador plantea que, mientras Federicci advertía la necesidad de ponerle límites al impulso que se le estaba dando a esta perspectiva, Vasco, entre tanto, la defendía exponiendo sus bondades (Cf. Arboleda, R., 1986, p. 1-2).
} 
fue la diferencia conceptual y metodológica que se identificó entre los marcos generales del currículo y los programas curriculares para cada área. Mientras que en los primeros se hacía una apuesta conceptual que rescataba los presupuestos de la nueva educación y establecía relaciones con los planteamientos de Jean Piaget, en los segundos la propuesta respondía a enfoques de corte conductual e instruccional que no eran consistentes con lo propuesto en el ámbito teórico.

Lo cierto es que los Marcos Generales del Currículo (versión de 1981), con respecto al área de Español y Literatura, señalan que el enfoque orientador es el semántico-comunicativo. Desde esta perspectiva "se busca que el niño desarrolle las cuatro habilidades comunicativas: hablar, escuchar, leer y escribir. Es decir, se espera que escuche y lea comprensivamente y que se exprese, tanto oralmente como por escrito, con propiedad y corrección" (Marcos generales del currículo, Español y Literatura, 1981. p. 33).

Investigadoras como Rincón y Ortiz (1985, p. 35) sostuvieron para aquella época que optar por el enfoque semántico-comunicativo constituía un notable avance frente a las Guías para maestros diseñadas por la Misión Pedagógica Alemana, en tanto que a través de este se introducen elementos semánticos, funcionales y pragmáticos del lenguaje, lo cual permitía superar el abordaje morfosintáctico preponderante en la enseñanza de la lengua. Sin embargo, al analizar los programas curriculares del área se evidenciaron las contradicciones e inconsistencias entre el enfoque teórico propuesto y las prescripciones del trabajo en aula, cuyo énfasis en la enseñanza de la lectura estaba de nuevo puesto en la decodificación y en la mirada perceptivo-motora de este proceso (Cf. Rincón y Ortiz, 1986, p. 37-39). Una de estas contradicciones se observa en las orientaciones metodológicas de los Programas Curriculares de Primer Grado, en los que si bien, por un lado, se sugiere tener en cuenta los intereses de los niños, partir del contexto lingüístico, enseñar las palabras en oraciones con sentido y no en sílabas ni en letras aisladas y establecer un orden para la enseñanza, por otro lado, se prescribe incluso el orden de presentación de las palabras y se instituye el procedimiento combinado.

En este escenario se puede aducir, entonces, que si bien hubo una intención expresa de introducir el enfoque semántico-comunicativo a través de esta política curricular, lo que ocurrió fue todo lo contrario: los programas curriculares empoderaron una perspectiva conductual, de corte perceptivo motor, que promovió el método de palabras normales. Por su parte, las editoriales se ciñeron a las indicaciones de estos programas curriculares, dejando de lado o adaptando delusoriamente los postulados de los marcos generales del área de Español y Literatura.

\section{Los Lineamientos Curriculares y los métodos de enseñanza: dos caminos disímiles}

Los años noventa constituyeron para Colombia un profundo cambio en términos de la redefinición de los principios éticos y políticos que empezaban a orientar el desarrollo del país, en razón de la promulgación de la nueva Carta Constitucional de 1991. Desde allí, la educación se asumió como un derecho y se proclamó la nueva Ley General de Educación en 1994. En este contexto, la 'autonomía' escolar marcó un derrotero importante en la redefinición del currículo; así, cada institución podría organizar las áreas, definir los contenidos pertinentes para su proyecto de formación, adaptar los mismos a las necesidades regionales y optar por métodos de enseñanza y organización de actividades formativas, dentro de los lineamientos establecidos por el MEN (Ley General de Educación, art. 77).

Es en este escenario donde el Ministerio emite en 1998, los Lineamientos Curriculares para el área de Lengua Castellana. En estos se introduce una concepción de lenguaje orientada hacia la construcción de la significación, a través de la construcción de diversos códigos y formas de simbolizar. Además, se definen cinco ejes alrededor de los cuales pensar las propuestas curriculares y el trabajo pedagógico de aula: 1) los procesos de construcción de sistemas de significación, 2) los procesos de interpretación y producción de textos, 3) los procesos culturales y estéticos asociados al lenguaje, 4) los principios de interacción y los procesos culturales implicados en la ética de la comunicación y 5) los procesos de desarrollo del pensamiento.

Especialmente, los dos primeros ejes dan cuenta de las perspectivas desde las cuales se asume la enseñanza inicial de la lectura y la escritura. En particular, el eje relativo a la construcción de sistemas de significación estará abiertamente orientado por una perspectiva psicogenética del aprendizaje de la lengua y circunscrito al enfoque constructivista. Con respecto a la conceptualización del proceso lector se plantea que

Leer es un proceso de construcción de significados a partir de la interacción entre el texto, el contexto y el lector. El significado, a diferencia de lo que sostenía el modelo perceptivo motriz de la lectura, no está solo en el texto, tampoco en el contexto ni en el lector, sino en la interacción de los tres factores, que son los que, juntos, determinan la comprensión. (Lineamientos Curriculares de Lengua Castellana, 1998, p. 72) 
Es de anotar allí, que por primera vez en los cambios legislativos que atravesaron estas tres décadas, dichas orientaciones curriculares no optan por un método de enseñanza de la lectura, pero en contraste señalan una perspectiva conceptual desde la cual se sugiere enfocar el trabajo en el aula. Pareciera que esta apuesta responde a un voto de confianza en la formación del maestro y en su capacidad para el diseño de un currículo contextualizado, y, de hecho, su propia formulación contó con la participación de una parte importante del gremio. Sin embargo, valdría la pena interrogar, en contraste con esta historia de prescripciones curriculares y diseños instruccionales 'a prueba de maestros', ¿qué acumulado de formación y de autonomía podrían tener los docentes para elaborar sus propias propuestas curriculares? La respuesta a esta pregunta podría explicar, en parte, por qué a pesar del avance conceptual que suponen estos lineamientos, en los textos escolares que se continuaron usando subsistió la línea establecida por la renovación curricular anterior.

En este orden de ideas, es claro el distanciamiento que se plantea en los lineamientos con respecto a este tipo de textos escolares y sus métodos instituyentes para enseñar a leer. Allí, en lugar de promoverse el uso de una cartilla o libro de texto, se sugiere a los maestros desarrollar criterios para la selección de materiales que respondan a diversas funciones de la lectura y a la calidad y diversidad de textos, lo cual implica el trabajo con diferentes géneros, formatos y tipologías textuales.

Como se evidencia en esta década, la política educativa y curricular y su agenciamiento a través del discurso oficial afectarían solo tangencialmente el diseño de las cartillas. De seguro, no fue fácil para la industria editorial trasladar el discurso constructivista al terreno del texto escolar; y, en este sentido, los métodos combinados continuaron ganando el consenso entre los diseñadores de los textos y, por tanto, suponemos, en sus usos activos en las escuelas.

\section{A modo de síntesis}

Los resultados del estudio hasta aquí expuestos, en efecto, nos permitieron identificar los enfoques pedagógicos predominantes para la enseñanza inicial de la lectura en el último tercio del siglo xx. Así, tenemos que la Educación Nueva y su expresión en la pedagogía activa con su método global permanecieron hasta entrada la década de los setenta, e, incluso, coexistieron inicialmente con el discurso de la Tecnología educativa. Este último enfoque toma fuerza en la década de los ochenta y viene a instalar lo que podríamos denominar una pedagogía instruccional o conductista de la lectura, cuya expresión coincide tanto con los métodos programados y métodos combinados como con el método de palabras normales. Posteriormente, en los inicios de la década de los noventa incursiona el enfoque o pedagogía constructivista, que viene a interpelar las concepciones derivadas de los anteriores, ya sea que presenten un énfasis en lo perceptivo-auditivo o en lo perceptivo-visual.

En cuanto a lo hallado en las cartillas y textos escolares, analizados grosso modo en perspectiva longitudinal, en la década de los setenta se caracterizan más por agenciar el método ideo-visual, manteniendo como principio básico la globalización. De ahí la insistencia en el desarrollo de la percepción ideo-visual, de lo que se deriva la preeminencia de narrativas icónicas vinculadas con situaciones cotidianas de los niños. Entre tanto, en la década de los ochenta, se instituye de nuevo en estos textos escolares el método de palabras normales, como procedimiento privilegiado para la introducción al código escrito. Método que se conservará en gran parte de los textos producidos en la década de los noventa, con lo que se perpetúa la propuesta general avalada en los Programas Curriculares para el área de Español y Literatura (1983). El cambio en algunos de los textos, como ya señalamos, fue adjetivo, dado que se varió en la materialidad o sustancia expresiva, pero no en la sustancia del contenido. Podemos afirmar aquí que el enfoque constructivista no alcanza a impactar los diseños de estos materiales educativos (cartillas o textos escolares para primer grado), entre otros, porque los interpela, e, incluso, los presenta como innecesarios.

En síntesis, del método ideo-visual o global que pervivió hasta los años setenta y que pretendió resolver el problema de la enseñanza de la lectura que tenía su énfasis en el deletreo memorístico y repetitivo - recordemos, para dar paso a 'la alegría de leer con entusiasmo', partiendo de frases significativas que expresaban estados emocionales y situaciones vinculadas al infante- se retorna en las décadas de los ochenta y noventa a las palabras generadoras o "palabras normales". Un método, que debemos decir, fue similar al identificado en la primera mitad del siglo xx con la pedagogía objetiva, en el cual hay una primacía del dominio auditivo por encima del aspecto visual, pues la imagen aquí "representa un sonido o una articulación para luego analizar la sílaba y el sonido y después representarlos en su signo, y poco a poco, con las palabras conocidas formar frases y luego oraciones" (Rincón, 2003, p. 147).

Por otra parte, los estudios de Rey (2001) y de Rincón (2003), que constituyeron la base de nuestro estado del arte sobre el objeto en cuestión, nos mostraron la estrecha relación entre las diferentes escuelas pedagógicas y las maneras de enseñar la 
lengua escrita a través de esos dispositivos ideológicos y pedagógicos que constituyen las cartillas. También demuestran la correspondencia entre el saber-poder y la incidencia de las hegemonías conservadora o liberal en las pedagogías de la lectura en la primera mitad del siglo xx: de la pedagogía objetiva a la pedagogía católica y, de ahí, a un aparente salto cualitativo con la pedagogía activa. Pero como vemos, el saber pedagógico no es lineal o evolutivo, más bien comprende retrocesos, fragmentos, múltiples variantes y todo aquello que es 'innovador' para una época, retorna clásico o tradicional en otra (Cf. García, 2015).

Ahora bien, en nuestra caracterización, si bien se demuestra que las cartillas como dispositivo pedagógico ya no refieren estrictamente a estos asuntos de orden ideológico (político) o dogmático (religioso), en términos de enfoques para enseñar a leer, la tecnología educativa sí desplaza los desarrollos de la pedagogía activa e instaura la concepción conductista en la lectura. Así también, el tipo de enseñanza a la que podría haber dado lugar el enfoque constructivista queda en una gran incógnita en términos prácticos. Por ello hay que anotar finalmente, en relación con la política, que cada discurso 'renovador' de la enseñanza se yuxtapone al anterior, y, entre tanto, la industria editorial va reacomodando su producción y adaptando sus textos al vaivén de los mismos.

La comprensión general de esta historia reciente de la enseñanza de la lectura que esbozamos hasta aquí, seguramente podrá dar algunas luces sobre muchas de las concepciones, métodos y prácticas que configuran hoy en día esta enseñanza. Desde nuestra propia experiencia, tanto en aulas de primer grado como en procesos de formación inicial y continua de maestros para esta alfabetización inicial, podríamos aventurarnos a afirmar, desde ya, que todo aquello que pervive en las actuales pedagogías de la lectura está constituido de ecos o fragmentos de estos discursos pasados, polifonía que se ha erigido en torno a este saber tan decisivo y fundamental en la escuela: enseñar a leer.

\section{Referencias bibliográficas}

Arboleda, R. (1986). Sobre la reforma curricular: el caso Español y Literatura. Disponible en: www.pedagogica. edu.co/storage/rce/articulos/18_12notas.pdf. (Recuperado en abril de 2012)

Agudelo, R. y Ballesteros, B. (1983). Comparación de dos métodos para la enseñanza de la lectura y la escritura. Segunda edición. Bogotá: Centro de Investigaciones CIUP. Universidad Pedagógica Nacional.

Braslavsky, B. (1962). La querella de los métodos en la enseñanza de la lectura. Sus fundamentos psicológicos y la renovación actual. Argentina: Kapelusz.
Bonafé, J. (2008). "Los libros de texto como práctica discursiva". En: Revista de la Asociación de Sociología de la educación 1, (1), 62-73.

Cardoso, N. (2001). "Los textos de lectura en Colombia. Aproximación histórica e ideológica. 1827-1917". En: Revista Educación y Pedagogía, XII, p. 29-30. Medellín: Universidad de Antioquia, Facultad de Educación.

Cardoso, N. (2002). "Los textos de lectura como dispositivos ideológicos en Colombia 1872-1930”. En: Nación, Educación, Universidad y manuales Escolares en Colombia: Tendencias Historiográficas Contemporáneas. Barranquilla: Fondo de Publicaciones, Universidad del Atlántico.

De Castro, M., et al. (1994). La enseñanza de la lengua escrita y de la lectura. Desde preescolar hasta tercer grado de educación básica. Bogotá: Sociedad Colombiana de Pedagogía.

Decroly \& Boon, G. (1950). Iniciación general al método Decroly y ensayo de aplicación a la escuela primaria. Quinta edición. Buenos Aires: Losada.

Escolano, A. (1998). Historia ilustrada del libro escolar en la España de la postguerra a la reforma educativa. Madrid: Fundación Germán Sánchez Ruiperez.

Escolano, A. (2001). "Sobre la construcción histórica de la manualística en España”. En: Manuales y Textos Escolares. Revista Educación y Pedagogía, XIII, n.o 29-30 (enero - septiembre). Medellín: Facultad de EducaciónUniversidad de Antioquia.

Ferreiro, E. \& Teberosky, A. (1979). Los sistemas de escritura en el desarrollo del niño. México: Siglo XXI editores.

Fandiño, G. (1985). Lectura y escritura. Bogotá: Centro de Enseñanza Desescolarizada, Universidad Santo Tomás.

García, N. (2015). “Las pedagogías de la lectura en Colombia: una revisión de estudios que se enfocan en el texto escolar durante la primera mitad del siglo xx". En: Lenguaje, 43, (1), 85-110.

Goodman, K. (1982). El proceso de lectura: consideraciones a través de las lenguas y del desarrollo. En Ferreiro \& Gómez (comps.). Nuevas perspectivas sobre los procesos de lectura y escritura. México: Siglo xxi editores.

Goodman, Y. (1997). "El conocimiento del niño sobre las raíces de la alfabetización y sus implicancias para la escuela". En Lectura y vida, 12, (1), p. 5-9.

Helg, A. (2001). La educación en Colombia: 1918-1957. Bogotá: Universidad Pedagógica Nacional y Plaza \& Janés.

Herrera, G. (s/a) Las cartillas de primeras letras en la educación colombiana. Disponible en línea: http://www. susaeta.com.co/pagina/hija-de-noticias/259. 
Jiménez, A. y Figueroa, H. (2002). Historia de la Universidad Pedagógica. Bogotá: Centro de Investigaciones de la Universidad Pedagógica Nacional, CIUP.

Martínez, A, et al. (2003). Currículo y modernización. Cuatro décadas de educación en Colombia. Bogotá: Editorial Magisterio.

Melo, J. O. (1999). Alegría de leer. Disponible en línea: http:// www.banrepcultural.org/node/73396

Ministerio de Educación Nacional (1990). Propuesta curricular piloto para el grado cero: marco político, conceptual y pedagógico. Bogotá.

Mougniotte, A. (1998). "Los métodos de enseñanza y de trabajo". En: Avanzini, G. (comp.). La pedagogía hoy. México: Fondo de Cultura Económica.

Luzuriaga, L. (1961). Métodos de la nueva educación. Buenos Aires: Losada.

Quiceno, H. (2008). "Manual escolar: pedagogía y formas narrativas". En: Educación y Pedagogía, III, (29 y 30).

Rey, A. (2000). La enseñanza de la lectura en Colombia. Una aproximación desde el análisis del discurso. Bogotá: Universidad Distrital-Colciencias.

Rincón, B. (2003). La enseñanza de la lectura y la escritura en Colombia 1870-1936. Una mirada desde la práctica pedagógica. Bogotá: Editorial Magisterio.

Rincón, G. \& Ortiz, C. (1985). “La reforma curricular y los programas de lectoescritura”. En: Revista Educación y cultura, 3, p. 34 -39.

Uhía, A. (1998). Orientaciones sobre lectura y escritura en la básica primaria. Bogotá: Educar Editores.

Villegas, 0. (1996). Escuela y lengua escrita. Competencias comunicativas que se actualizan en el aula de clase. Bogotá: Magisterio.

Zuluaga, O. (1987). Pedagogía e historia. Bogotá: Foro Nacional por Colombia.
Zuluaga, O. (2003). “De Comenio a Herbart”. En: Pedagogía y Epistemología. Bogotá: Magisterio.

\section{Cartillas y textos escolares}

Cuervo, H. et al. (1984). Armonía del lenguaje. Barranquilla: El Cid.

Charry, J. (1973). Nueva cartilla Charry. Bogotá: Voluntad,

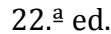

Godoy, M. (1996). Madrigal 1 inicial. Bogotá: Grupo Editorial Norma.

Osorio, J. (1984). Nacho. Libro inicial de lectura. Medellín: Susaeta.

Ramírez, A. (1989). Festival. Español y Literatura 1. Bogotá: Voluntad, 7aㅡ ed.

Villabona, C. (1987). Trampolín. Educación básica primaria. Bogotá: Voluntad, 2ª ed.

s. a. (1971). Sonata: enseñanza primaria, primer grado. Bogotá: Voluntad, Santillana.

\section{Documentos oficiales}

MEN (1969). Guías para el maestro. Desarrollo, Parcelación, Anexo.

----- (1981). Marcos Generales de los Programas Curriculares.

----- (1998). Lineamientos generales del área de lengua castellana.

(1963). Decreto 1710.

----- (1974). Decreto 080.

----- (1976). Decreto 088.

----- (1978). Decreto 1419.

(1984). Decreto 1002. 